\title{
Examining the Factors Contributing to Fintech Peer-to-peer Lending Adoption
}

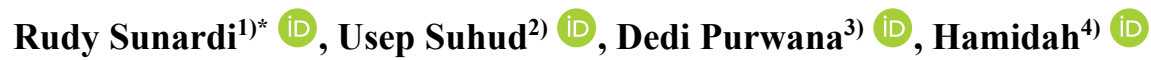 \\ 1)2)3)4) Universitas Negeri Jakarta, Indonesia \\ Jl. Rawamangun Muka, Jakarta Timur \\ ${ }^{1)}$ rudysunardi_9917920022@mhs.unj.ac.id, ${ }^{2)}$ usuhud@unj.ac.id, ${ }^{3)}$ dpurwana@unj.ac.id, ${ }^{4)}$ hamidah@unj.ac.id
}

\begin{abstract}
Background: Peer-to-peer (P2P) lending platform is one of key disruptive business models in financial technology. It bridges lenders and borrowers directly. Researchers have studied the leverage mechanism behind the P2P lending platform.

Objective: This research proposes an enhanced technology acceptance model (TAM) to investigate how consumers embrace $\mathrm{P} 2 \mathrm{P}$ lending platforms using quality of service and perceived risk as drivers of trust.

Methods: This research uses structural equation modeling (SEM) to test the hypothesised connections between the latent variables.

Results: The findings show that users' trust, perceived usefulness, and perceived ease of use in P2P lending platforms significantly influence attitudes towards adoption. Meanwhile, consumers' perceived risk in using P2P lending platforms is unaffected by the quality of service.

Conclusion: The estimated model is consistent with the results shown in previous studies. The findings of the current research are useful for fine-tuning platform marketing plans and putting strategic goals into actions. For future research, we suggest including more variables to better understand the adoption intention of P2P lending platforms.
\end{abstract}

Keywords: Adoption intention, Peer-to-peer lending, Structural equation modeling, Technology acceptance model

Article history: Received 14 July 2021, first decision 18 August 2021, accepted 13 September 2021, available online 28 October 2021

\section{INTRODUCTION}

Peer-to-peer (P2P) lending platform is a thriving business in fintech sector. The first P2P lending development platform and pioneer in this field is Zopa, a UK platform that directly connects lenders and borrowers, serving only UK citizens [1]. As of May 2020, five billion pounds in personal loans lent to over 470,000 UK consumers have been made available through Zopa that have generated returns for their lenders and helped borrowers realise their personal goals and desires. In 2006, two P2P lending platforms, Prosper and Lending Club, appeared in the US and became the most popular in US market today. In the US, Europe and China, the number of platforms is continuously increasing; and there are now hundreds of platforms offering millions of loans.

A comprehensive survey of $\mathrm{P} 2 \mathrm{P}$ lending by Zhao et al. [2] specifically summarises some of the world's major P2P lending platforms and provides a systematic taxonomy for them, comparing different types of working mechanisms in details. Some critical challenges and open problems have been identified in this area need to be solved, including pricing, mechanism enhancement, risk management, privacy preservation and personalisation. However, research from the user's perspective on adopting P2P lending is still rare in the last six years, including in Indonesia. Among the few are a study, which examines individuals as the user [3] and Small and medium-sized enterprises (SMEs) as the user [4].

Considering the gap in the literature, the purpose of this research is to enrich the understanding of the user's intention as an individual in adopting a P2P lending platform. Understanding user behavioural intentions by considering the contributing factors is critical in refining and developing a platform, as well as the marketing strategy. This research applied technology acceptance model (TAM) to understand the effect of some variables on the adoption of new technologies at the individual level [5]. Among the models to analyse adoption of technology at end-users, TAM was found to perform the best compare with TPB (the theory of planned behavior) or UTAUT (the unified theory of acceptance and use of technology) [6]. Moreover, TAM is a flexible model that can be changed or expanded with more factors to suit the purposes of this research, such as trust, perceived risk and quality of service.

\footnotetext{
${ }^{*}$ Corresponding author
} 
The following is how the rest of the paper is organised: section 2 introduces the literature review, describing the conceptual framework and hypotheses, as well as the rationales; section 3 describes the methodology, namely the data collection and instruments development; section 4 describes the results;section 5 presents the discussion; and section 6 concludes the paper.

\section{LITERATURE REVIEW}

\section{A. Fintech P2P lending}

The finance sector all over the world has been leveraging the advancement of information technology, resulting in an innovation known as financial technology or fintech [7]. It is a rapidly evolving and dynamic sector with specific business strategies [8] and it has transformed the way financial service companies work and engage with their clients. This changes the paradigm of conventional financial services, resulting in a significant disruption [9]. P2P lending platform is described as a "financial exchange" that occurs directly between individuals without the need of a typical financial institution as a facilitator [10]. The new internet-based service allows users to borrow money directly from one another [2] [11] [12] [13] and has now become a key business model and brought about disruption in the financial sector in general.

\section{B. Hypotheses Development and the Proposed Model}

To explain the impacts of factors on consumer behaviors and intentions, Davis [5] introduced TAM, based on the theory of reasoned action (TRA) model [14].

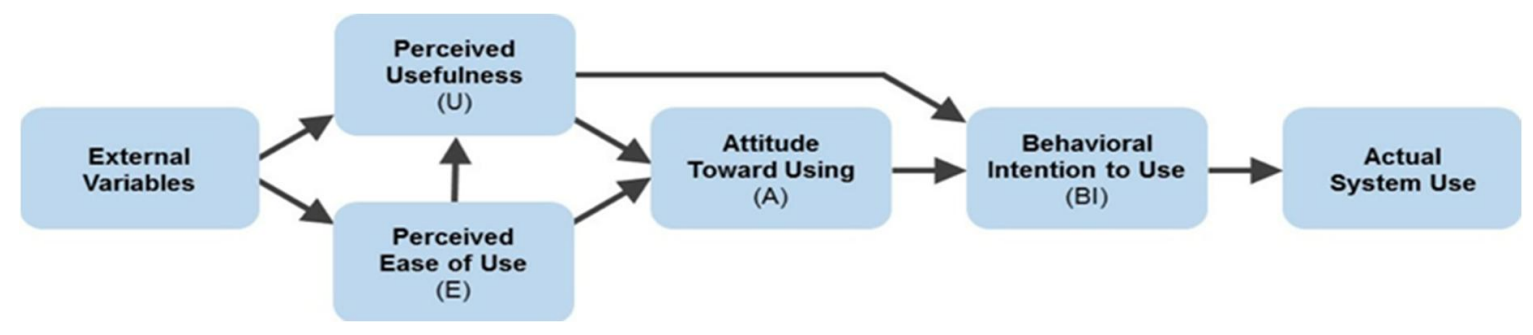

Fig. 1 Technology Acceptance Model [5]

As shown in Fig. 1, TAM suggests that perceived usefulness (PU) and perceived ease of use (PE) describe individual users' adoption intentions. PU is when user perceive an increase their job performance after using a specific system. The degree to which individuals feel that utilising the system is simple and straightforward is referred to as PE.

Since its original publication, scholars have consistently supported TAM in numerous settings, and it has been utilised extensively in technology adoption studies throughout the last decades. TAM could be a fundamental model that can be changed or expanded in a variety of ways. As a result, numerous modifications, including other theories, have emerged intending to analyse fintech, as prior researches on mobile P2P lending applications [12], fintech services for bank users [15], and fintech and banking [16].

\section{1) Perceived Usefulness}

In the TAM, PU is a factor that is extensively employed in the adoption of information systems. It is defined as the extent the new technology increases consumer's job efficiency [5]. In this research, PU refers to the fact that consumers prefer to utilise the service if they believe that the P2P lending platform will have a positive impact [12]. Extensive empirical research on information technology adoption over the last decade has revealed that PU may have a beneficial influence on consumer's intentions toward fintech and banking [16], mobile wallet [17], smart-home-application [18], smart-application for learning [19] and Uber mobile application [20]. As a result, the following hypothesis was proposed:

Hypothesis 1 (H1): PU has a positive influence on adoption intention (AI).

\section{2) Perceived Ease of Use}

Another critical component in the TAM is perceived ease of use (PE). It is defined as the amount of work required to use this new technology [5]. In this research, PE refers to the degree to which customers are at ease and willing to learn how to utilise the P2P lending platform. In previous studies, scholars have shown a substantial relationship between PE and attitudes toward new technology adoption in fintech and banking [16], smart home application [18], smart application for learning [19], Uber mobile application [20], mobile P2P lending application [12], mobile banking [21]. Furthermore, PE had an impact significantly on PU in new technology adoption intention on mobile learning [22], 
smart-home-application [18], mobile banking [21] and P2P lending application [12]. As a result, the following hypotheses were generated:

Hypothesis 2 (H2): PE has a positive influence on AI.

Hypothesis 3 (H3): PE has a positive influence on PU.

3) Trust

Trust (TR), according to Lewis and Weigert [23], is a complex, multifaceted entity that plays an important role in commercial interactions. TR has always been focused on adoption and is frequently utilised as a secondary foundation for attracting consumers in addition to PU and PE. Because of the large and high-dimensional data involved in the service, the function of TR in financial technology application scenarios is even more essential. Previous research has shown the factors that affect TR in fintech innovation adoption, such as customer service and satisfaction [24]; brand image, government support, perceived risk [15]; and information quality and service quality [25]. Therefore, it is important to research how TR affects the attitudes of potential users and their willingness to adopt. As a result, the following hypothesis was formed:

Hypothesis 4 (H4): TR has a positive influence on AI.

\section{4) Quality of Services}

Quality of Service (QS) at its most basic relates to a customer's comparison of service expectations with perceptions of what the service provider provides [26] [27]. QS is crucial for the performance and profitability of a firm. High QS will give the company a competitive advantage in the market in two ways, firstly by increasing attraction and acquisition of new customers and secondly by retaining existing customers by providing provide high quality and make them happy for more reuse, in this way, there is less cost and efficiency and higher profit for companies [28]. QS is a broad assessment of a service that influences business performance, adoption intentions and customer satisfaction [29]. In prior researches, scholars have demonstrated how QS has a positive impact on TR [25] [30] [24]; and a negative impact on Perceived Risk (PR) [25] [31] [32]. As a result, the following hypotheses were generated:

Hypothesis 5 (H5): QS has a positive influence on TR.

Hypothesis 6 (H6): QS has a negative influence on PR.

\section{5) Perceived Risk}

Perceived risk (PR) is defined by Schierz et al. [33] as the expectation of losses. Meanwhile, Ko et al. [34] expressed public relations as consumers' views of the varied and conflicting outcomes of buying a product or service. Consumer behaviour may be understood using PR theory. PR is a type of TR deficiency and most researchers feel that PR is the primary factor influencing technology adoption [32] [21]. In this paper, PR refers to the perceived privacy risk that customers see when using fintech services, such as personal data leak, or transaction data and other personal information. According to a previous research, risk perception is the most crucial element influencing the adoption of cloud technology [35]; mobile banking [21] [36]; fintech services [15]. As a result, the following hypothesis was formed based on prior research:

Hypothesis 7 (H7): PR has a negative influence on TR.

\section{Conceptual Framework}

Based on previous research and theoretical concept, this research uses TAM, TR, QS, and PR to analyse the adoption intention of the P2P lending platform. The dependent variable is a behavioral adoption intention (AI), whereas PU, PE, TR, QS, and PR were the independent variables. A graphical representation of the proposed hypothesis is presented in Fig. 2. The combination provides a complete set of constructs: PE, PU, TR, QS, PR, and AI, which can improve the prediction of user behaviour in terms of adoption intention of the P2P lending platform. Table 1 shows the hypotheses tested in this study.

TABLE 1

RESEARCH HYPOTHESES IN THIS STUDY

\begin{tabular}{|c|c|c|c|c|}
\hline \multicolumn{4}{|c|}{ Research hypotheses Hypothesized path } & \multirow{2}{*}{$\begin{array}{l}\text { Sources } \\
{[5][12][18][19][20][17][16]}\end{array}$} \\
\hline $\mathrm{H} 1$ & $\mathrm{PU}$ & $\rightarrow$ & AI & \\
\hline $\mathrm{H} 2$ & $\mathrm{PE}$ & $\rightarrow$ & AI & {$[5][12][15][18][19][20][16][22]$} \\
\hline $\mathrm{H} 3$ & $\mathrm{PE}$ & $\rightarrow$ & PU & [12] [21] [18] [19] [22] \\
\hline $\mathrm{H} 4$ & $\mathrm{TR}$ & $\rightarrow$ & AI & {$[24][30][25][19]$} \\
\hline H5 & QS & $\rightarrow$ & TR & {$[24][30][25]$} \\
\hline H6 & QS & $\rightarrow$ & PR & {$[32][31][25]$} \\
\hline $\mathrm{H} 7$ & PR & $\rightarrow$ & TR & {$[35][15][25][37]$} \\
\hline
\end{tabular}


Sunardi, Suhud, Purwana, \& Hamidah

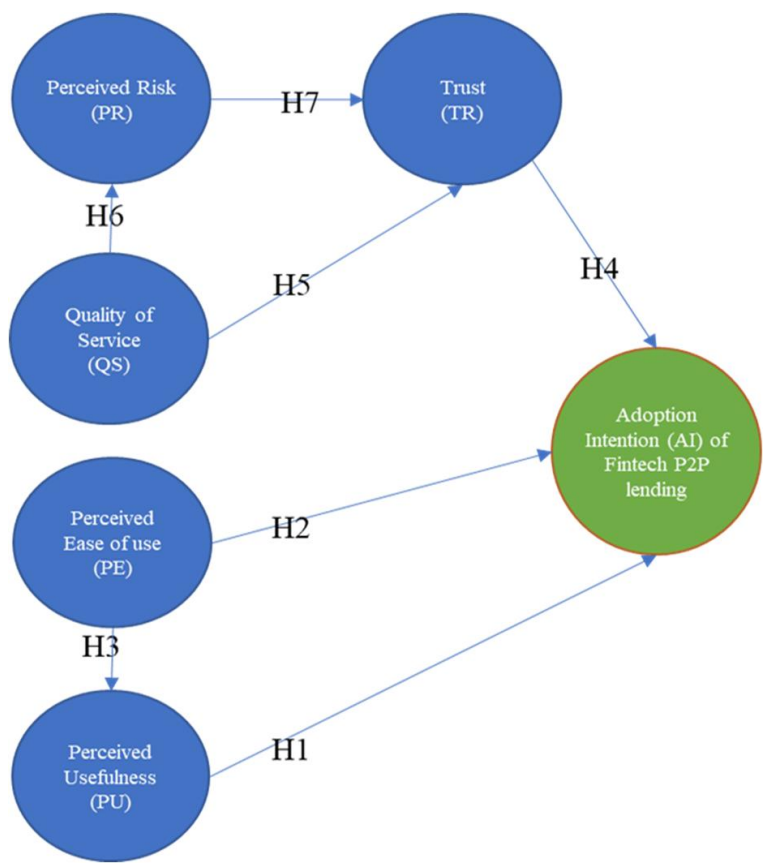

Fig. 2 Proposed hypothesis model

TABLE 2

CHARACTERISTICS OF THE SAMPLE

\begin{tabular}{|c|c|c|c|}
\hline Demographic Variable & Category & Frequency & Percentage \\
\hline \multirow{2}{*}{ Gender } & Male & 168 & $65.2 \%$ \\
\hline & Female & 90 & $34.8 \%$ \\
\hline \multirow{8}{*}{ Age } & $<20$ & 2 & $0.8 \%$ \\
\hline & $20-24$ & 9 & $3.5 \%$ \\
\hline & $25-29$ & 35 & $13.6 \%$ \\
\hline & $30-34$ & 80 & $31.0 \%$ \\
\hline & $35-39$ & 53 & $20.5 \%$ \\
\hline & $40-44$ & 44 & $17.1 \%$ \\
\hline & $45-49$ & 22 & $8.5 \%$ \\
\hline & $\geq 50$ & 13 & $5.0 \%$ \\
\hline \multirow{4}{*}{ Marital Status } & Married & 199 & $77.1 \%$ \\
\hline & Single & 34 & $13.2 \%$ \\
\hline & Divorce & 17 & $6.6 \%$ \\
\hline & Partner Died & 8 & $3.1 \%$ \\
\hline \multirow{5}{*}{ Education } & $<$ High School & 3 & $1.1 \%$ \\
\hline & High School & 32 & $12.4 \%$ \\
\hline & Associate Degree & 115 & $44.6 \%$ \\
\hline & Bachelor & 83 & $32.2 \%$ \\
\hline & Master / Doctoral & 25 & $9.7 \%$ \\
\hline \multirow{5}{*}{ Employee Status } & Student & 8 & $3.1 \%$ \\
\hline & Employee & 159 & $61.6 \%$ \\
\hline & Self-employed & 78 & $30.2 \%$ \\
\hline & Pension & 10 & $38.8 \%$ \\
\hline & Unemployed & 3 & $1.2 \%$ \\
\hline \multirow{6}{*}{ Income (IDR) } & $<51,000,000$ & 28 & $10.8 \%$ \\
\hline & $5,000,000-10,000,000$ & 67 & $26.0 \%$ \\
\hline & $10,000,001-15,000,000$ & 40 & $15.5 \%$ \\
\hline & $15,000,001-20,000,000$ & 74 & $28.7 \%$ \\
\hline & $20,000,001-25,000,000$ & 29 & $11.2 \%$ \\
\hline & $>25,000,000$ & 20 & $7.8 \%$ \\
\hline \multirow{2}{*}{$\mathrm{P} 2 \mathrm{P}$ lending platform usage } & Never & 40 & $15.5 \%$ \\
\hline & Usually & 218 & $84.5 \%$ \\
\hline
\end{tabular}




\section{METHODS}

\section{A. Data Collection}

The data collection through a survey was conducted online. Microsoft Form questionnaires were distributed to 290 respondents in Java, Indonesia, from September to December 2020. The survey's subjects are randomly selected consumers who have used P2P lending platforms, mobile banking, internet banking or other fintech services. The definition of the P2P lending platform and the goal of the study were stated in the questionnaire's introduction. Akseleran, Amartha, Crowdo, CROWDE, Danamas, Gradana, Investree, Koinworks, Mekar and Modalku were presented as sample legal (licensed) P2P lending platforms in the questionnaire.

Following the first selection, faulty questionnaires with insufficient response times and random filling were eliminated, leaving 258 acceptable responses with an effective response rate of $88.96 \%$. Table 2 displays the descriptive statistical findings of questionnaires that examined respondent's demographic factors such as gender, age, marital status, education level, employee status, income and P2P lending platform user status.

Persons aged 25-39 years old (65.1\%) make up the most significant proportion in terms of age distribution, and these consumers are always the first to adopt new technologies and lifestyles. It means this sampling is appropriate. In terms of the number of users of $\mathrm{P} 2 \mathrm{P}$ lending platforms, the proportion was $84.5 \%$, which is high and an indicator of the popularity of the fintech among the respondents, or technology users in general.

\section{B. Instrument Development}

When designing the questionnaire, this paper refers to previous relevant research and makes the appropriate expansions and adjustments according to the characteristics of the P2P lending platform studied in this paper, as seen in Table 3. TR was adopted from Lien et al. [16] and Singh and Sinha [17]; PE was adopted from Johnson et al. [38] and Lien et al. [16]; PU was adopted from Z. Hu et al. [15] and Lien et al. [16]; QS was adopted from Ryu and Ko [25]; PR was adopted from Johnson et al. [38]. The scale consisted of six variables as external influencing factors, and each variable consisted of four to six measurement variables. A six-point Likert Scale was used to score the 29 items, and the options were: strongly disagree, disagree, slightly disagree, slightly-agree, agree and strongly agree.

TABLE 3

MEASUREMENT INSTRUMENTS

\begin{tabular}{|c|c|c|c|}
\hline Variables & Items & Measurement & Sources \\
\hline \multirow{5}{*}{ PU } & PU1 & P2P lending platforms can meet the needs of customers & {$[16]$} \\
\hline & PU2 & Customers save much time when using the $\mathrm{P} 2 \mathrm{P}$ lending platform & [16] \\
\hline & PU3 & Using the P2P Lending platform increases customer work efficiency & [16] \\
\hline & PU4 & Customers can access many utilities attached when using the P2P lending platform & [16] \\
\hline & PU5 & Overall, the P2P lending platforms are useful to me & [15] \\
\hline \multirow{6}{*}{$\mathrm{PE}$} & PE1 & The operations performed in the $\mathrm{P} 2 \mathrm{P}$ lending service are simple for customers & [16] \\
\hline & PE2 & Instructions on the $\mathrm{P} 2 \mathrm{P}$ lending service system are clear and easy to understand & [16] \\
\hline & PE3 & Customers can interact with the P2P lending service system everywhere & {$[16]$} \\
\hline & PE4 & Learning to use the P2P lending platform would be easy for me & [38] \\
\hline & PE5 & Using a P2P lending platform is not mentally challenging & {$[38]$} \\
\hline & PE6 & Using a P2P lending platform is straightforward & [38] \\
\hline \multirow{5}{*}{ TR } & TR1 & P2P lending service has good information security ability & {$[16]$} \\
\hline & TR2 & $\mathrm{P} 2 \mathrm{P}$ lending service is provided by reputable providers only & {$[16]$} \\
\hline & TR3 & Customers feel confident when using the $\mathrm{P} 2 \mathrm{P}$ lending platform & {$[16]$} \\
\hline & TR4 & I trust P2P lending service keeps my personal information safe & {$[17]$} \\
\hline & TR5 & I trust $\mathrm{P} 2 \mathrm{P}$ lending service apps and transactions done by $\mathrm{P} 2 \mathrm{P}$ lending & {$[17]$} \\
\hline \multirow{4}{*}{ QS } & QS1 & P2P lending platform quickly responds to my needs & [39] \\
\hline & QS2 & $\mathrm{P} 2 \mathrm{P}$ lending platform has the knowledge to answer my questions & [39] \\
\hline & QS3 & P2P lending platform understands my specific needs & [39] \\
\hline & QS4 & $\mathrm{P} 2 \mathrm{P}$ lending platform is always willing to help me & [39] \\
\hline \multirow{5}{*}{ PR } & PR1 & I would not feel safe providing personal private information over a P2P lending platform & [38] \\
\hline & PR2 & I am worried about other people gaining access to my account if I use the $\mathrm{P} 2 \mathrm{P}$ lending platform & [38] \\
\hline & PR3 & I would not feel secure sending sensitive information across P2P lending platforms & {$[38]$} \\
\hline & PR4 & Using a P2P lending platform would involve more financial risk when compared to traditional ways of lending & [38] \\
\hline & PR5 & I do not think there is any real financial risk associated with the $\mathrm{P} 2 \mathrm{P}$ lending platform & [39] \\
\hline \multirow{4}{*}{ AI } & AI1 & If not already using, customers intend to use the P2P lending platform soon & [16] \\
\hline & AI2 & If using, customers want to continue using the $\mathrm{P} 2 \mathrm{P}$ lending platform & [16] \\
\hline & AI3 & Customers will recommend $\mathrm{P} 2 \mathrm{P}$ lending platforms to their neighbours or relatives & {$[16]$} \\
\hline & AI4 & I will use the $\mathrm{P} 2 \mathrm{P}$ lending platform in the future & [39] \\
\hline
\end{tabular}




\section{RESUlTS}

The data is analysed in three stages: exploratory factor analysis and reliability analysis, confirmatory factor analysis, and structural equation modeling and hypothesis testing. The first stage was performed on all items in a questionnaire using SPSS version 23, reported in section A. The confirmatory factor analysis and structural equation modeling were utilized in the study's measurement and structural model analysis. This study, in particular, uses the AMOS version 23 for data analysis. Sections B and C show the measurement and structural model analysis results, respectively.

\section{A. Exploratory Factor Analysis (EFA) and Reliability Analysis}

EFA is a method that may be used in SPSS to evaluate scales of questionnaire items. An EFA's goal is to explain a multidimensional data collection with fewer variables. After a questionnaire has been verified, a procedure known as confirmatory factor analysis (CFA) can be utilised [43]. The 39 items were subjected to an EFA using a Direct Oblimin rotation with Delta $=0$. In this study, the six factors (i.e., PE, PU, TR, PR, QS and AI) were used to determine the pattern of the structure in the instrument and were used to create a pattern matrix. By identifying inappropriate items, TR2, TR3, QS1, QS2 and AI1 were removed because there were cross-loading or low loading factors $(\leq 0.6)[40]$.

TABLE 4

RELIABILITY AND VALIDITY MEASURES

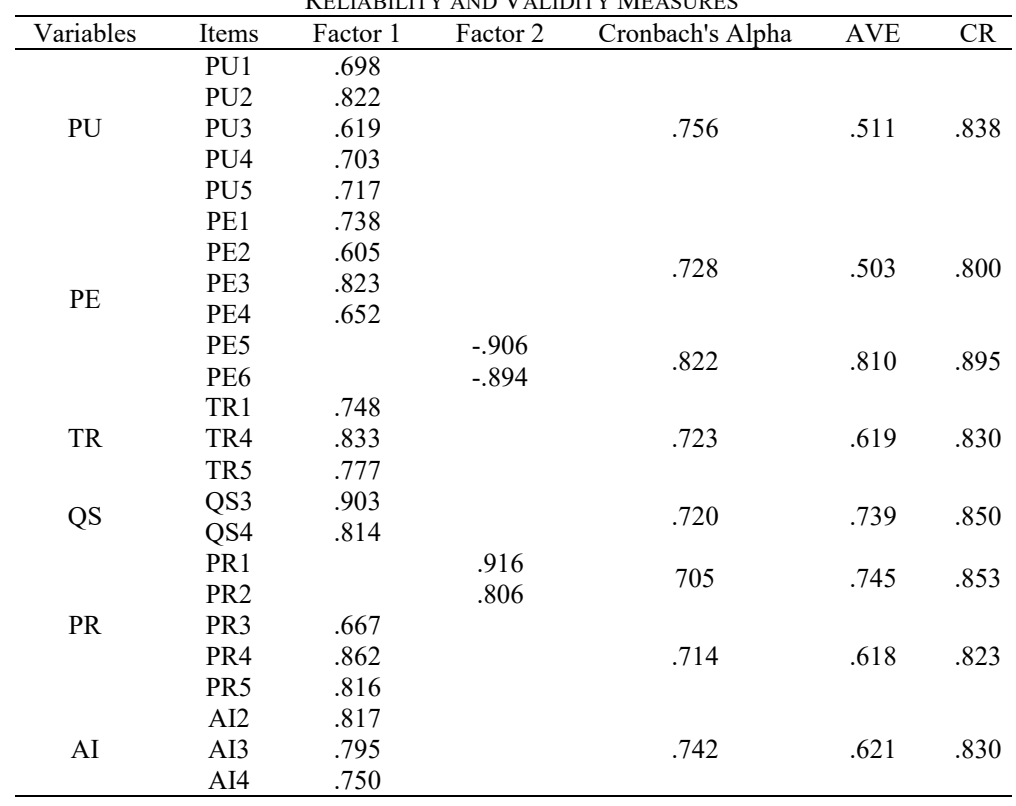

The amount of consistency or stability of the measurement findings, which indicates the dependability of the questionnaire items, is referred to as reliability. Cronbach's alpha was employed in this study to assess the data's internal consistency. According to Taber [41], the sample's Cronbach's alpha should be more than 0.7. Then, three primary metrics were employed to assess an instrument's convergent validity: (1) the factor loadings must be greater than 0.60 ; (2) the composite reliability (CR) must be greater than or equal to 0.70; and (3) the average variance extracted (AVE) must be greater than or equal to 0.50 [42]. As shown in Table 4, all latent variables' Cronbach's alpha, CR and AVE were more than the critical values, suggesting that the model has excellent reliability and convergent validity.

\section{B. Confirmatory Factor Analysis (CFA)}

CFA is a subset of structural equation modeling (SEM) that focuses on measurement models, especially the connections between observed measures or indicators (e.g., test scores, test items, behavioral observation ratings) and latent variables or factors [43]. The factorial structure of the predicted six-factor measurement model was tested using CFA. The preliminary CFA results are described in the P-value test of close fit (where $\mathrm{P}>0.05$ indicates a good model fit). The Root Mean Square Error of Approximation (RMSEA) $=0.08$ indicates a reasonable model fit, and RMSEA $<$ 0.05 indicates a good fit to data. In case of poor fit, then modification indices are explored to see if it was possible to remove items with lower loadings on the standardised solution matrix and improve the model fit. After removing poor items (i.e., PU1, PU3, PU4, PE1, PE2, PE5, PE6, PR1, PR2), an additional CFA was performed on the refined scale. As 
seen in Fig. 3, all these variables were allowed to interact. Each of the 15 items was only permitted to load on the primary interest factor and not on any other factors.

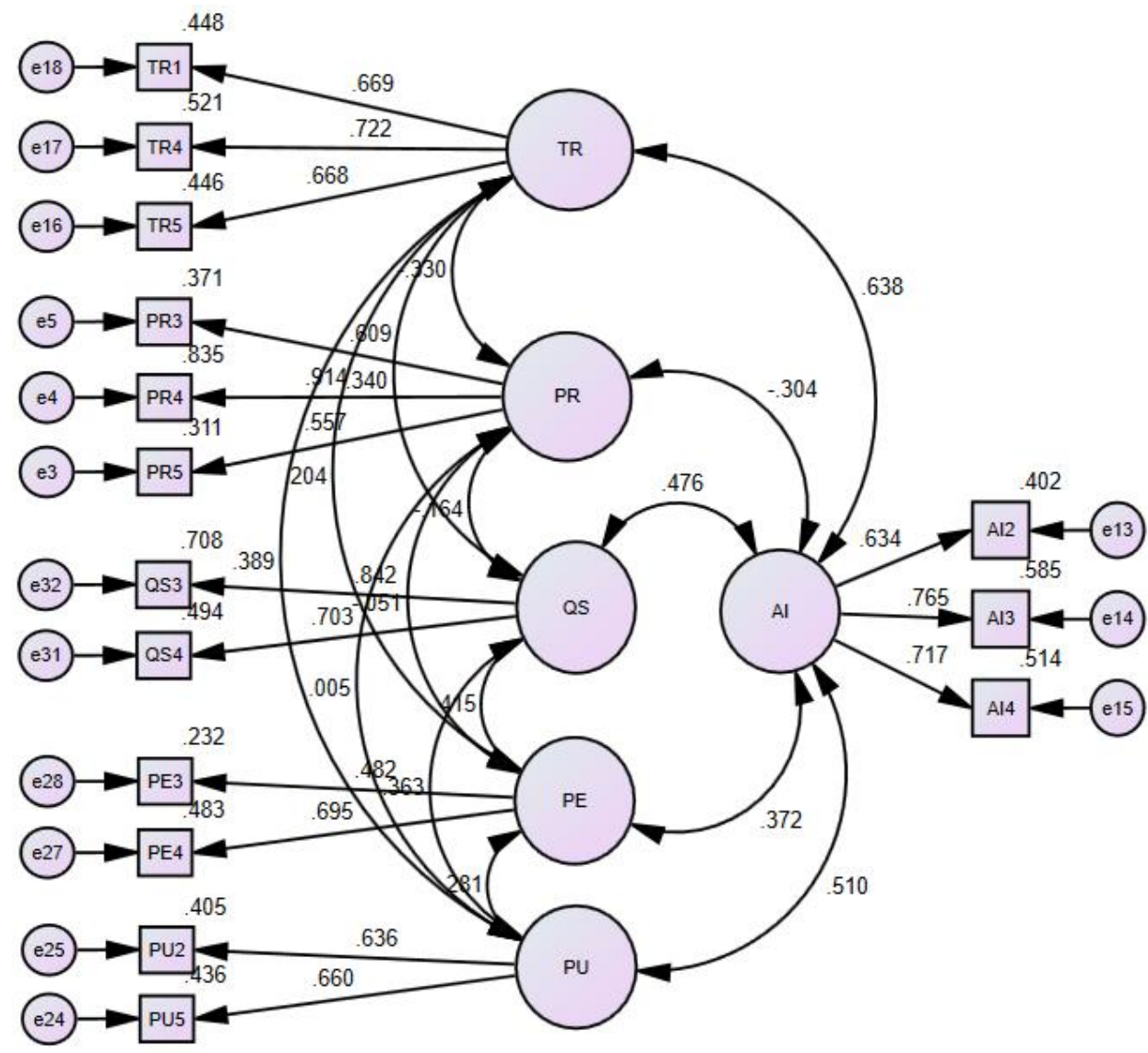

Fig. 3 The proposed model in CFA with standardised estimates

The detailed results of the CFA analysis with CMIN, P, CMIN/DF, SRMR, RMSEA, TLI, and CFI are shown in Table 5. All key values in the proposed model meet the CFA model fit.

\begin{tabular}{rccccccr}
\multicolumn{9}{c}{ TABLE 5 } \\
CFA MODEL FIT & & & \\
\hline & CMIN & P & CMIN/DF & SRMR & RMSEA & TLI & CFI \\
\hline Proposed model & 73.670 & .522 & .982 & .0398 & .000 & 1.002 & 1.000 \\
Recommended model fit & Small & $>.05$ & $\leq 2$ & $\leq .08$ & $\leq .08$ & $>.90$ & $\geq .95$ \\
& & & {$[44]$} & {$[45]$} & {$[46]$} & {$[47]$} & {$[48]$} \\
\hline
\end{tabular}

\section{Structural Equation Modeling (SEM) and Hypothesis Testing}

SEM is an extension of CFA that tests particular hypothesised connections between latent variables. SEM methods with AMOS graphics were used to assess the fit of the proposed model's measurement and structural components. As shown in Fig. 4, uses the SEM model to generate the standardised path coefficient $(\beta)$ and t value, which were used to evaluate the hypotheses given. 


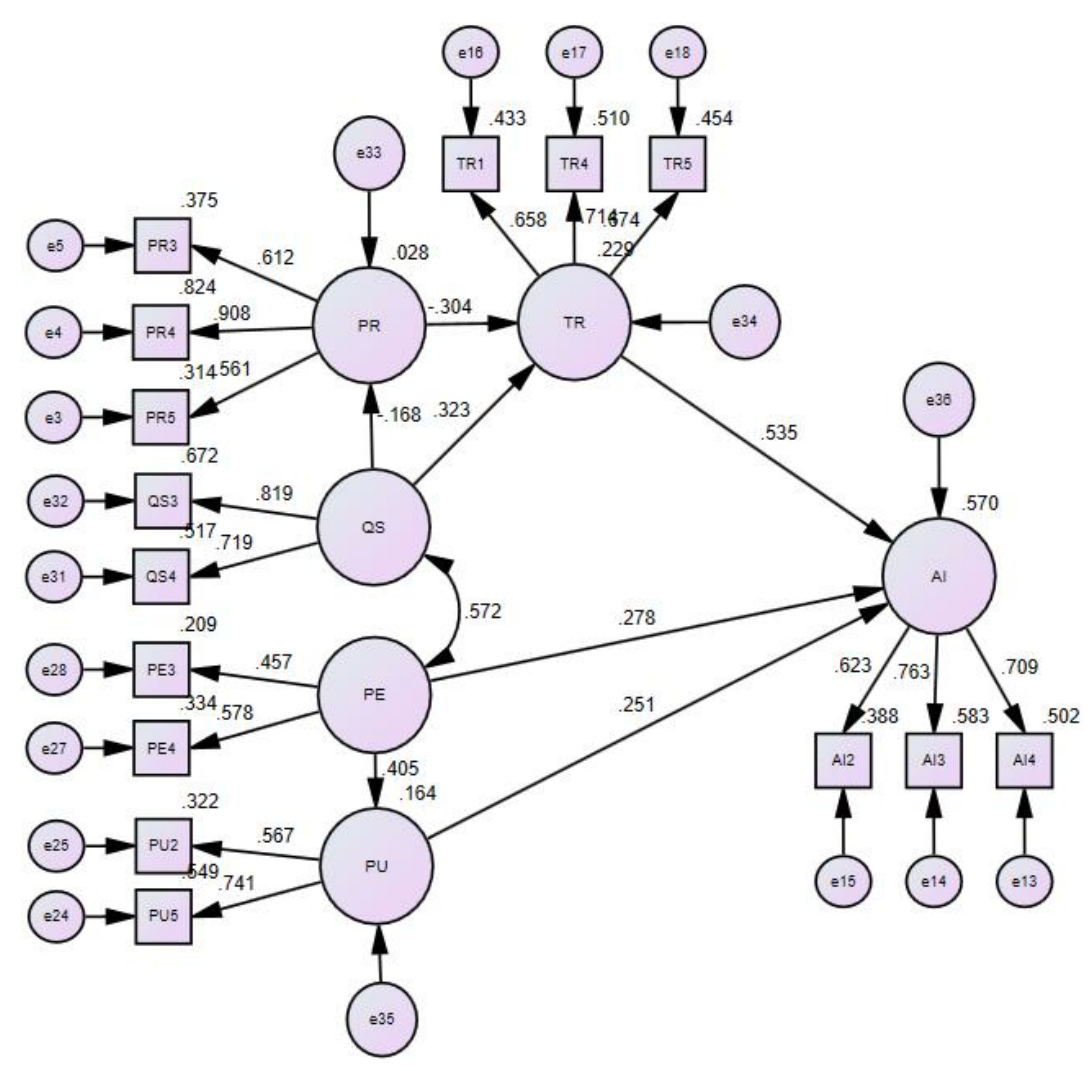

Fig. 4 The proposed model in SEM with standardised estimates

The detailed results of the SEM analysis with CMIN, P, CMIN/DF, SRMR, RMSEA, TLI, and CFI are shown in Table 6. All critical values in the proposed model meet the SEM model fit.

TABLE 6

\begin{tabular}{rccccccc}
\multicolumn{10}{c}{ SEM MODEL FIT } \\
\hline & CMIN & P & CMIN/DF & SRMR & RMSEA & TLI & CFI \\
\hline Proposed model & 97.537 & .116 & 1.189 & .0562 & .027 & .977 & .982 \\
\cline { 2 - 4 } & Small & $>.05$ & $\leq 2$ & $\leq .08$ & $\leq .08$ & $>.90$ & $\geq .95$ \\
Recommended model fit & {$[44]$} & {$[45]$} & {$[46]$} & {$[47]$} & {$[48]$} \\
\hline
\end{tabular}

TABLE 7

HYPOTHESIS TESTING RESULT

\begin{tabular}{|c|c|c|c|c|c|c|c|c|}
\hline \multirow{2}{*}{$\begin{array}{c}\begin{array}{c}\text { Research } \\
\text { hypotheses }\end{array} \\
\text { H1 }\end{array}$} & \multicolumn{3}{|c|}{ Hypothesized path } & \multirow{2}{*}{$\frac{\text { Estimate }}{.251}$} & \multirow{2}{*}{$\begin{aligned} \text { S.E. } \\
.145\end{aligned}$} & \multirow{2}{*}{$\frac{t \text {-value }}{2.559}$} & \multirow{2}{*}{$\frac{\mathrm{p} \text {-value }}{.010}$} & \multirow{2}{*}{$\frac{\text { Interpretation }}{\text { Accepted }}$} \\
\hline & $\mathrm{AI}$ & $\leftarrow$ & PU & & & & & \\
\hline $\mathrm{H} 2$ & $\mathrm{AI}$ & $\leftarrow$ & PE & .278 & .192 & 2.352 & .019 & Accepted \\
\hline H3 & PU & $\leftarrow$ & $\mathrm{PE}$ & .405 & .164 & 2.710 & .007 & Accepted \\
\hline $\mathrm{H} 4$ & $\mathrm{AI}$ & $\leftarrow$ & TR & .535 & .128 & 5.718 & $* * *$ & Accepted \\
\hline H5 & TR & $\leftarrow$ & QS & .323 & .062 & 3.652 & $* * *$ & Accepted \\
\hline H6 & TR & $\leftarrow$ & PR & -.304 & .081 & -3.698 & $* * *$ & Accepted \\
\hline $\mathrm{H} 7$ & PR & $\leftarrow$ & QS & -.168 & .057 & -2.090 & .037 & Accepted \\
\hline
\end{tabular}

According to Berger and Sellke [49], if t-value $>1.96$, statistically significant at P-value $<0.05$ level of confidence. If t-value $>2.58$, statistically significant at the P-value $<0.01$ level of confidence. If t-value $>3.29$, statistically significant at $\mathrm{P}$-value $<0.001$ level of confidence. Table 7 shows the results of hypothesis testing with estimates, standard errors, $\mathrm{t}$-values, and P-values. 


\section{DISCUSSION}

As demonstrated in Table 7, all the research hypotheses were accepted, showing statistically significant path coefficients $(\mathrm{t}$ value $>1.96, \mathrm{P}$ value $<0.05)$. The relationship between the dependent variable and the independent variable was direct: Adoption Intention (AI) was significantly impacted by PU (H1: $\beta=0.251, t=2.559)$. The result is consistent with the basic assumptions of TAM, where usefulness is the central premise of attitudes towards the use of new technology [12]. This testing result is in line with the previous studies on the drivers of smart home technology adoption [18], Uber mobile application [20], mobile wallet [17], fintech and banking [16]. This result shows that customers are willing to use the P2P lending platform because this service offers advantages over existing solutions, namely multi-finance and banking.

AI was significantly impacted by PE $(\mathrm{H} 2: \beta=0.278, \mathrm{t}=2.352)$. This testing result shows that perceived ease of use significantly impacts customers' intention to use P2P lending platforms in Indonesia. The result is in line with the previous studies on the adoption of mobile learning [22], fintech services for bank users [15], fintech and banking [16].

Perceived ease of use (PE) was found to be significantly associated with PU (H3: $\beta=0.598, t=2.991$ ). This result indicates that perceived ease of use positively affects perceived usefulness towards customers in adopting P2P lending platforms. The result is in line with the previous studies on the adoption of P2P lending apps [12], and the drivers of smart home technology [18].

AI was significantly impacted by TR $(\mathrm{H} 4: \beta=0.535, \mathrm{t}=5.718)$. This is shown in the descriptive analysis, showing that the highest mean of the reliable variable (TR) is 5.71. This implies that users have a high degree of trust in the P2P lending platform and feel that the service is reliable and promising. It can be concluded that users trust P2P lending platforms because some are registered with the Financial Services Authority (OJK). The result is in line with the previous study by researchers such as Khlaisang et al. [19], Al-dweeri et al. [24], Ryu and Ko [25], Goutam et al. [30]. Quality of services $(\mathrm{QS})$ was found to be significantly associated with TR $(\mathrm{H} 5: \beta=0.323, \mathrm{t}=3.652)$; this result indicates that a $\mathrm{P} 2 \mathrm{P}$ lending platform that provides good service will increase customers' trust; hence, the rate of adoption. The result in line with the previous studies such as Ryu and Ko [25], and Goutam and Gopalakrishna [30].

Perceived risk (PR) was found to be significantly associated with TR $(\mathrm{H6}: \beta=-.304, \mathrm{t}=-3.698)$; this result showed that perceived risk is proven to be negatively significant towards customer's trust in using P2P lending platform. The result aligns with the previous study on the adoption of online shopping [30] and in the airline industry [32]. However, this result is different when considering the perceived risk influencing customer adoption directly, such as in a study by Kurniawan [3]. The relationship between QS and PR $(\mathrm{H} 7: \beta=-0.1268, \mathrm{t}=-2.090)$ indicates that the quality of services is proven to be negatively significant towards customers' perceived risk in using P2P lending platforms. The result is consistent with the previous studies on the adoption of fintech [25] and hydrogen-electric motorcycle [31].

\section{A. Contributions}

This work contributes to the growing body of literature in P2P lending by clarifying the relationship between these constructs. As a result, the findings of our study are useful for refining the marketing strategy of platforms and realising strategic goals; understanding user behavioural intentions by considering influencing factors is critical to building a platform in the digital era.

\section{B. Limitations}

The study has several limitations that should be addressed in future research. First, data for this research were collected from only one country, Indonesia. Since country culture was found to affect the relevance of the constructs such as perceived risk [50] and quality of service [51], future research should test the scale invariance of this measurement before applying it to other countries. Second, the participants for this study were sampled based on prior experience with the P2P lending platform, the employed approach to examine only participants who used a P2P lending platform at least once. The literature argues that the less familiar and more ambiguous the object being rated, the greater the tendency for common method bias [52], which could affect the factor structure. Future research should replicate this study's findings with samples that differ regarding the extent of $\mathrm{P} 2 \mathrm{P}$ lending platform familiarity.Third, the emerging financial technology innovations are generally related to government regulations such as standards and practice guarantees in the industry. The literature shows that customer protection is one of the main discussion themes in $\mathrm{P} 2 \mathrm{P}$ lending platform research [53]. The factor regulation and the association's roles are more factors for further research to better understand the adoption intention of $\mathrm{P} 2 \mathrm{P}$ lending platforms.

\section{CONCLUSIONS}

The empirical study presented in this work reveals that: first, the hypothesis test results of this model show that TR, PU and PE play important roles. QS had a substantial indirect positive influence on TR, and QS had a indirect negative influence on PR in terms of adoption intention. Second, PR can influence consumer's opinions about AI in P2P lending 
platforms. The mechanism is that PR has a negative influence on TR, whereas TR encourages consumers to engage in $\mathrm{P} 2 \mathrm{P}$ lending platforms. This demonstrates that consumer's perceptions on $\mathrm{P} 2 \mathrm{P}$ lending platforms impact on the lowering degree of TR in services. Platform development must include methods to minimise PR to users to strengthen TR in products and services, boosting user's willingness to utilise the platform.

Author Contributions: Rudy Sunardi: conceptualisation, methodology, software, formal analysis, writing - original draft. Usep Suhud, Dedi Purwana and Hamidah: validation, investigation, supervision, writing - review and editing.

Funding: This research received no specific grant from any funding agency.

Conflicts of Interest: The authors declare no conflict of interest.

\section{REFERENCES}

[1] A. Milne and P. Parboteeah, "The Business Models and Economics of Peer-to-Peer Lending," SSRN Electron. J., 2016, doi: $10.2139 /$ ssrn.2763682.

[2] H. Zhao, Y. Ge, Q. Liu, G. Wang, E. Chen, and H. Zhang, "P2p lending survey: platforms, recent advances and prospects," ACM Trans. Intell. Syst. Technol., vol. 8, no. 6, pp. 1-28, 2017.

[3] R. Kurniawan, "Examination of the Factors Contributing To Financial Technology Adoption in Indonesia using Technology Acceptance Model: Case Study of Peer to Peer Lending Service Platform," in 2019 International Conference on Information Management and Technology (ICIMTech), Aug. 2019, vol. 1, pp. 432-437, doi: 10.1109/ICIMTech.2019.8843803.

[4] M. Rosavina, R. A. Rahadi, M. L. Kitri, S. Nuraeni, and L. Mayangsari, "P2P lending adoption by SMEs in Indonesia," Qual. Res. Financ. Mark., vol. 11, no. 2, pp. 260-279, 2019, doi: 10.1108/QRFM-09-2018-0103.

[5] F. D. Davis, "A technology acceptance model for empirically testing new end-user information systems: Theory and results," Massachusetts Institute of Technology, 1985.

[6] M. M. Rahman, M. F. Lesch, W. J. Horrey, and L. Strawderman, "Assessing the utility of TAM, TPB, and UTAUT for advanced driver assistance systems," Accid. Anal. Prev., vol. 108, pp. 361-373, 2017.

[7] S. R. Das, "The future of fintech," Financ. Manag., vol. 48, no. 4, pp. 981-1007, 2019.

[8] G. Dorfleitner, L. Hornuf, M. Schmitt, and M. Weber, "Definition of FinTech and Description of the FinTech Industry," in FinTech in Germany, Cham: Springer International Publishing, 2017, pp. 5-10.

[9] A. F. Carmona et al., "Competition issues in the area of financial technology (Fintech)," Policy Dep. Econ. Sci. Qual. Life Policies Eur. Parliam., 2018.

[10] A. E. Omarini, "Peer-to-Peer Lending: Business Model Analysis and the Platform Dilemma," Int. J. Financ. Econ. Trade, pp. 31-41, 2018, doi: 10.19070/2643-038x-180005.

[11] Q. Yang and Y.-C. Lee, "Critical factors of the lending intention of online P2P: moderating role of perceived benefit," in Proceedings of the 18th Annual International Conference on Electronic Commerce: e-Commerce in Smart connected World, 2016, pp. 1-8.

[12] S. Lee, "Evaluation of Mobile Application in User's Perspective: Case of P2P Lending Apps in FinTech Industry.," TIIS, vol. 11, no. 2, pp. 1105-1117, 2017.

[13] N. Zhang and W. Wang, "Research on Balance Strategy of Supervision and Incentive of P2P Lending Platform," Emerg. Mark. Financ. Trade, vol. 55, no. 13, pp. 3039-3057, 2019.

[14] I. Ajzen and M. Fishbein, "The prediction of behavior from attitudinal and normative variables," J. Exp. Soc. Psychol., vol. 6, no. 4, pp. 466-487, 1970.

[15] Z. Hu, S. Ding, S. Li, L. Chen, and S. Yang, "Adoption intention of fintech services for bank users: An empirical examination with an extended technology acceptance model," Symmetry (Basel)., vol. 11, no. 3, p. 340, 2019.

[16] N. T. K. Lien, T.-T. T. Doan, and T. N. Bui, "Fintech and Banking: Evidence from Vietnam," J. Asian Financ. Econ. Bus., vol. 7, no. 9, pp. 419-426, 2020.

[17] N. Singh and N. Sinha, "How perceived trust mediates merchant's intention to use a mobile wallet technology," J. Retail. Consum. Serv., vol. 52, p. 101894, 2020.

[18] M. Hubert, M. Blut, C. Brock, R. W. Zhang, V. Koch, and R. Riedl, "The influence of acceptance and adoption drivers on smart home usage," Eur. J. Mark., vol. 53, no. 6, pp. 1073-1098, 2019, doi: 10.1108/EJM-12-2016-0794.

[19] J. Khlaisang, T. Teo, and F. Huang, "Acceptance of a flipped smart application for learning: a study among Thai university students," Interact. Learn. Environ., vol. 29, no. 5, pp. 772-789, 2021, doi: 10.1080/10494820.2019.1612447.

[20] S. Min, K. K. F. So, and M. Jeong, "Consumer adoption of the Uber mobile application: Insights from diffusion of innovation theory and technology acceptance model," J. Travel Tour. Mark., vol. 36, no. 7, pp. 770-783, 2019.

[21] S. A. Raza, A. Umer, and N. Shah, "New determinants of ease of use and perceived usefulness for mobile banking adoption," Int. J. Electron. Cust. Relatsh. Manag., vol. 11, no. 1, pp. 44-65, 2017.

[22] J. A. Kumar, B. Bervell, N. Annamalai, and S. Osman, "Behavioral Intention to Use Mobile Learning: Evaluating the Role of Self-Efficacy, Subjective Norm, and WhatsApp Use Habit," IEEE Access, vol. 8, pp. 208058-208074, 2020, doi: 10.1109/ACCESS.2020.3037925.

[23] J. D. Lewis and A. Weigert, “Trust as a Social Reality,” Soc. Forces, vol. 63, no. 4, pp. 967-985, Jan. 1985, doi: 10.2307/2578601.

[24] R. M. Al-dweeri, Z. M. Obeidat, M. A. Al-dwiry, M. T. Alshurideh, and A. M. Alhorani, "The impact of e-service quality and e-loyalty on online shopping: moderating effect of e-satisfaction and e-trust," Int. J. Mark. Stud., vol. 9, no. 2, pp. 92-103, 2017.

[25] H.-S. Ryu and K. S. Ko, "Sustainable Development of Fintech: Focused on Uncertainty and Perceived Quality Issues," Sustainability, vol. 12 , no. 18 , p. $7669,2020$.

[26] C. Gronroos, "A Service Quality Model and its Marketing Implications,” Eur. J. Mark., vol. 18, no. 4, pp. 36-44, 1984, doi: 10.1108/EUM0000000004784. 
[27] A. Parasuraman, V. A. Zeithaml, and L. L. Berry, "A conceptual model of service quality and its implications for future research," J. Mark., vol. 49, no. 4, pp. 41-50, 1985.

[28] E. W. Anderson, C. Fornell, and D. R. Lehmann, “Customer satisfaction, market share, and profitability: Findings from Sweden,” J. Mark., vol. 58 , no. 3, pp. 53-66, 1994.

[29] O. O. Jaiyeoba, T. T. Chimbise, and M. Roberts-Lombard, "E-service usage and satisfaction in Botswana," African J. Econ. Manag. Stud., vol. 9, no. 1, pp. 2-13, Jan. 2018, doi: 10.1108/AJEMS-03-2017-0061.

[30] D. Goutam and B. Gopalakrishna, "Customer loyalty development in online shopping: An integration of e-service quality model and commitment-trust theory," Manag. Sci. Lett., vol. 8, no. 11, pp. 1149-1158, 2018.

[31] H.-S. Chen, B.-K. Tsai, and C.-M. Hsieh, "Determinants of consumers' purchasing intentions for the hydrogen-electric motorcycle," Sustainability, vol. 9, no. 8, p. 1447, 2017.

[32] A. R. Ghotbabadi, S. Feiz, and R. Baharun, "The relationship of customer perceived risk and customer satisfaction,” Mediterr. J. Soc. Sci., vol. 7, no. $1 \mathrm{~S} 1$, p. 161,2016

[33] P. G. Schierz, O. Schilke, and B. W. Wirtz, "Understanding consumer acceptance of mobile payment services: An empirical analysis," Electron. Commer. Res. Appl., vol. 9, no. 3, pp. 209-216, May 2010, doi: 10.1016/j.elerap.2009.07.005.

[34] H. Ko, J. Jung, J. Kim, and S. W. Shim, "Cross-Cultural Differences in Perceived Risk of Online Shopping," J. Interact. Advert., vol. 4, no. 2, pp. 20-29, Mar. 2004, doi: 10.1080/15252019.2004.10722084.

[35] S. M. Ho, M. Ocasio-Velázquez, and C. Booth, "Trust or consequences? Causal effects of perceived risk and subjective norms on cloud technology adoption," Comput. Secur., vol. 70, pp. 581-595, 2017.

[36] C. A. Gumussoy, A. Kaya, and E. Ozlu, "Determinants of mobile banking use: an extended TAM with perceived risk, mobility access, compatibility, perceived self-efficacy and subjective norms," in Industrial Engineering in the Industry 4.0 Era, Springer, 2018, pp. 225238.

[37] P. K. Senyo and E. L. C. Osabutey, "Unearthing antecedents to financial inclusion through FinTech innovations," Technovation, vol. 98, p. $102155,2020$.

[38] V. L. Johnson, A. Kiser, R. Washington, and R. Torres, "Limitations to the rapid adoption of M-payment services: Understanding the impact of privacy risk on M-Payment services," Comput. Human Behav., vol. 79, pp. 111-122, 2018.

[39] H. S. Ryu, "What makes users willing or hesitant to use Fintech?: the moderating effect of user type," Ind. Manag. Data Syst., vol. 118, no. 3, pp. 541-569, 2018, doi: 10.1108/IMDS-07-2017-0325.

[40] R. C. MacCallum, K. F. Widaman, S. Zhang, and S. Hong, "Sample size in factor analysis.," Psychol. Methods, vol. 4, no. 1, p. 84, 1999.

[41] K. S. Taber, "The use of Cronbach's alpha when developing and reporting research instruments in science education," Res. Sci. Educ., vol. 48 , no. 6 , pp. 1273-1296, 2018.

[42] N. Luo, M. Zhang, and D. Qi, "Effects of different interactions on students' sense of community in e-learning environment," Comput. Educ., vol. 115, pp. 153-160, 2017.

[43] T. A. Brown, Confirmatory factor analysis for applied research. Guilford publications, 2015.

[44] B. M. Byrne, Structural Equation Modeling With Lisrel, Prelis, and Simplis. New York, NY, USA: Psychology Press, 1998.

[45] L. Hu and P. M. Bentler, "Cutoff criteria for fit indexes in covariance structure analysis: Conventional criteria versus new alternatives," Struct. Equ. Model. a Multidiscip. J., vol. 6, no. 1, pp. 1-55, 1999.

[46] M. W. Browne and R. Cudeck, "Alternative ways of assessing model fit," Sociol. Methods Res., vol. 21, no. 2, pp. 230-258, 1992.

[47] P. M. Bentler and D. G. Bonett, "Significance tests and goodness of fit in the analysis of covariance structures.," Psychol. Bull., vol. 88, no. 3, p. $588,1980$.

[48] P. M. Bentler, "Comparative fit indexes in structural models.," Psychol. Bull., vol. 107, no. 2, p. 238, 1990

[49] J. O. Berger and T. Sellke, "Testing a point null hypothesis: The irreconcilability of p values and evidence," J. Am. Stat. Assoc., vol. 82, no. 397 , pp. 112-122, 1987.

[50] P. K. Chopdar, N. Korfiatis, V. J. Sivakumar, and M. D. Lytras, "Mobile shopping apps adoption and perceived risks: A cross-country perspective utilizing the Unified Theory of Acceptance and Use of Technology," Comput. Human Behav., vol. 86, pp. 109-128, 2018.

[51] N. K. Malhotra, J. Agarwal, and G. Shainesh, "Does Country or Culture Matter in Global Marketing? An Empirical Investigation of Service Quality and Satisfaction Model with Moderators in Three Countries BT - Emerging Issues in Global Marketing: A Shifting Paradigm," J. Agarwal and T. Wu, Eds. Cham: Springer International Publishing, 2018, pp. 61-91.

[52] D. Zunino, F. F. Suarez, and S. Grodal, "Familiarity, creativity, and the adoption of category labels in technology industries," Organ. Sci., vol. 30, no. 1, pp. 169-190, 2019.

[53] R. R. Suryono, I. Budi, and B. Purwandari, "Detection of fintech P2P lending issues in Indonesia," Heliyon, vol. 7, no. 4, p. e06782, 2021. 